\title{
Research on Interactive Teaching Community of Autonomous Learning via Metacognitive Strategy
}

\author{
Sun Nian, Xu Yi, Qin Xuehan, Li Huan, Zhao Xiaojing, Wu Xianchao \\ Department of computer science and technology, Wuhan University of Technology, Wuhan, Hubei, China
}

\begin{abstract}
Network interactive teaching is a new teaching form on the basis of computer network under the influence of modern constructivist learning theory and cognitive psychology. Higher education has changed from teacher-centered model in which teaching language knowledge is the main part to student-centered model which focus on developing the ability of knowledge application and automatic learning. This paper uses metacognitive strategies, automatic learning, network teaching, interaction and other related theories to construct network interactive teaching community which based on automatic learning( $\mathrm{A}$ Research of Interactive Teaching Community via Constructing Automatic Learning on the Metacognition Strategy, RITC), to establish the supporting platform of network interactive teaching model , and the experimental results were analyzed through the investigation to prove the effectiveness of the community.
\end{abstract}

KEYWORD: Metacognitive Strategy; Automatic Learning; Interactive Teaching; Community

\section{RELATED RESEARCH}

\subsection{Automatic learning via metacognitive strategies}

Metacognitive strategy is a high-level execution skill, including planning, monitoring, and evaluating learning activities. It is a necessary condition for successfully planning, monitoring and evaluating the learning activities. It plays a key role in improving learning effect. In this process, the process of cognition of learners and the traditional teaching process have changed. In the traditional cognitive process, the teacher is the dominant part. Through teaching, knowledge is transferred to the learners who are in a passive position. But in metacognitive strategy, teacher is the facilitator who guides the learners.

Automatic learning refers to learners are not completely dependent on others. Learners carry on learning activities in the form of self- management. The concrete performances are setting the learning goal, deciding the learning content, choosing the learning strategies, monitoring the learning process, evaluating the learning results. Auto-determinism theory believes that, in the higher education of college students, automatic learning plays a vital role in the learning of university subjects. Modern psychology believes that if students want to learn automatically, they must have three conditions. The first is achieving a certain level of psychological development, the second is having the intrinsic learning motivation, and the third is having some learning strategies.

\subsection{Network teaching community}

Generally, the network learning community is an interactive and cooperative learning community which consists of a variety of learners and facilitators (including teachers, experts and etc.).In the computer network environment, members in the community take the network as communication tool, and communicate to acquire knowledge, accomplish tasks and form interactive relationship network. All members in the community have the same goal and interests, and they have the power and responsibility to create and maintenance the community. They share information, resources and each other's thoughts, ideas, originality and experience so that they can promote their own learning and development.

Network learning community is a virtual learning community based on internet. Learners carry on learning activities through the man-machine interaction model. The activities do not regard a class as a unit, and are based on students and facilitators' discussion and interaction on a specific topic, sharing experience and professional knowledge instead of teachers' explanation. The final goal is that the members in learning community construct their own knowledge system. 
The learner is the main part of network learning community. They get access to learning resources and control the learning process under the guide of the group which made up by facilitators. The facilitators, including teachers, mentors and experts, are the "organizers" and "operators" of network learning community. The facilitators provide help, including the knowledge, the network operation, and the affective interaction, for the students to overcome the difficulties in the learning process. Learning resources are mainly refers to digital information organized by hypertext and stored on the server, including text, graphics, images, audio, video, animation and etc. Network learning environment refers to the sum of dominant and recessive factors which are based on the network platform. The dominant environment mainly refers to the physical network and the network learning system, and the recessive environment mainly refers to the harmonious interpersonal relationship, strong study atmosphere, the appropriate organizational form of teaching, effective teaching strategy, standard organization and etc.

\subsection{Interaction in network teaching}

Traditional interaction in teaching refers to that educators (teachers) and learners (students) communicate with each other through a variety of ways. This interaction reflected more in the classroom teaching process and assessment of homework. HuXuhuai \& YangZhihe \& Chen Zhuanhong. 2012. In the modern network teaching model, there are some new features in teaching: The interaction is multidimensional, multidirectional, diverse, active, and the interactive content is rich.

\section{CONSTRUCTION OF RITC MODEL}

After years of teaching practice, combined with the teaching community and the concept of Role-learning courses, the basic framework of RITC is built. ShenChunhua. 2006. Students and teachers are the main participants to complete a common task. The RITC platform is based on the network environment. The basic structure of RITC which based on automatic learning, mainly take the student as the main body, and take the students' learning activities as a small units, build up an interactive teaching community with the basic theory of metacognitive strategies.

In the community, teachers should take the responsibility that making continuous progress, learn and design the class as a learning guider and a supporter. And students should complete the cognitive method and practice, and manage their own learning process, explore the knowledge, construct knowledge and other activities. The teachers and students should carry on teaching activities, learning activities, teaching evaluation together. In the community, interaction refers to understanding, reflection and sharing.

\section{CONSTRUCTION OF RITC PLATFORM}

Because of the complicated procedure of multiple roles and multiple tasks, teaching community requires real-time, participation, equality and interaction. The network learning (Web-based Learning) provides a very good learning community of practice platform. Network teaching is to use the functional and digital resources and other learning materials which can adapt to open and flexible distributed teaching environment to achieve a well-designed, learner-centered teaching method which faced anyone in anytime at any place.

Network teaching community is also called as the "Virtual Teaching Community". The main participants are teachers and students, and the main form is learning. Major activities are network learning and exchange of knowledge. RITC is mainly supported by The Web2.0 technology. The interpersonal relationship is more closely.

RITC is a network support environment organized by a certain teaching objectives, and some teaching strategies. The members in the community will be two-way communication. The platform consists of user management module, automatic learning interaction module, test module, operation module and the expansion module and other components. In the interaction module, students are the main body. When students encounter problems, they can choose the right means of communication according to the need. The online forum platform provides a platform to exchange ideas for the group. The real-time platform provides the real-time and automatic answering system. Students can discuss with teachers to solve a problem, but also can view the database records to search through the station. Teachers use the function of checking the dynamics of student to grasp the dynamics and adjust their teaching plans. Learning Assessment is that the system will give awards to the learners according to the evaluation of learners' learning so that students' sense of competition can be inspired, and the teachers can make the next step.

While the students acquiring nutrients in the community, they also contribute to the community. And in the community, learners form interactive relationship and eventually promote the growth of individual.

In the teaching community, teachers should always online so that they can solve the difficult problems in time from students. When the teachers found new problems, they do not tell students the answers. Teachers can let the students to do some 
studying on the related websites and do some report. Then the teachers will give some supplement or ask a new question.

In the community, teachers should always pay attention to the students' original learning and practical problems and adjust teaching activities according to the teaching environment. Teachers' guides not only help students to master knowledge, but also get experience from the deep reflection of the dynamics of students.

\section{IMPLEMENTATION OF RITC TEACHING}

\subsection{The design of teaching task}

In order to promote the cooperation and interaction between students and teachers, teachers should try to select some open, with a certain complexity of the real task. Because the cooperative learning is carried out in certain situations, in the process of creating task situation, not only we should consider the students' cognitive ability, knowledge, learning habits, but also the situation should be attractive to students, and reflect the dominant position of students and the leading role of teachers in the learning. In the interactive network teaching platform, we can easily render learning tasks by inserting labels, themes, writing text or web page, providing details about the mission statement of resources. In order to stimulate students to recall previously learned knowledge, for the content that include a large number of text and image, we can use word documents, PPT presentations and other form to upload. Linking to external web site to provide more extensive related resources for learners is also feasible.

\subsection{Division of study groups and activity}

Study groups formed by two or more individuals interact to find the methods to solve the problems. Teachers should provide enough multimedia learning resources and activities to the students on the network interactive teaching platform. In order to complete the common learning objectives, group members must cooperate with each other, such as to participate in the collection of network resources together, to complete the learning activities developed by teachers. Teachers can stimulate students' motivation to learn through the corresponding function of the network teaching platform. For example, teachers can set the deadline of submitting, the number of visits, size, post a notice about the standard of success, tell the learners what performance is acceptable and well received, allow learners to complete the task to cause a sense of accomplishment, and thus stimulate the willingness of automatic learning. In addition, teachers should use a variety of interactive tools to guide the learner from the process of self-expression to the process of listening to others' views. Thus students can get a lot of critical perspectives and multiple views, broaden their horizons, learn social interpersonal skills at the same time, and respect the rights of members to express their views and opinions, produce more possible learning space for development.

Each group submits the learning result and all groups discuss together to express the different opinions. The Interactive evaluation function on the network interactive teaching platform can be used between the groups to evaluate other groups.

Finally, teachers should summarize the study results, give some comments, and solve the problem left in the group learning. The teachers' evaluation is open and multi-objective, which is not only for the learning results, but also for the learning process. Because of the track record function on the network interactive teaching platform, in the evaluation process, the evaluation of the group members can be based on the number of their statement, speeches in the forum or chat room. In order to ensure the objectivity and authenticity, the evaluation of group process should be completed by the group members and teachers together. To promote the interaction between teachers and learners, Maslow, a humanistic psychologist, put the human needs into five levels. They are physiological needs, security needs, the need for love and belonging, the need for respect and the need for self-actualization. These needs have established innovative one-to-one teaching relationship, greatly promoted the study in the learning activity system. Although technology benefit to the establishment of the one-to-one learning relationship between the teachers and the students, it cannot maintain this relationship fundamentally. Activation of learning motivation is an activity through the whole process of classroom teaching. Teachers should not only arouse the students' interest at begin of the students' automatic learning activities, but also keep the students' curiosity in the process of students' automatic learning so that the automatic learning activities of students can be carried out. In the process of the excitation of students, they are not always in a passive state in the whole learning. They need to imply themselves that he want to understand this lesson and can infer other things from one fact. All group members should encourage each other, ensuring that his/her tasks and group learning tasks can be finished efficiently.

\section{ANALYSIS OF TEACHING EFFECT OF RITC}

In the RITC, due to the changes in classroom teaching, the evaluation methods for students also 
will be changed. According to Constructivist Teaching Theory, after the establishment of teaching community, the evaluation model will transform from the one-way model to the community model. The evaluation of process replace the evaluation of results, and the process of teaching replace "after the teaching", and the multiple evaluation replace the single evaluation, and the continuous evaluation replace the episodic evaluation, and the circular evaluation replace the summative evaluation. Therefore, the method of evaluation for the students' learning results has transferred from the formal to informal. In this method of evaluation, through the contact and interaction with students, teacher will form an opinion and judgment on student. LaoLing \& LuoShuanglan. 2008. The method of the evaluation replaces or becomes a supplement for the past "grade", "scores" and produce good effect in students. Its advantage is that, it provides interactive learning opportunities and metacognitive strategies for students in the community and records the learning process of each student in every period, masters the trajectory of each student. Therefore, the teacher's evaluation on the students now consists of the online test of automatic study ability (20\%), the interactive performance $(10 \%)$, the after-school exercises $(10 \%)$, the experiment result $(20 \%)$ and the test paper score $(40 \%)$, which used to be made up of the regular grade $(20 \%)$, the test paper score $(60 \%)$, and the experiment result $(20 \%)$. The test paper score (40\%) and community teaching pattern is echoed. The online test of automatic study ability (20\%) is mainly testing the automatic learning ability of students. The interactive performance $(10 \%)$ is also included in the scope of examination to improve the initiative of students' participation in the interactive community. The after-school exercises $(10 \%)$ is also recorded in the final grade, which encourages students to study seriously, think independently or learn with others; otherwise the student will not be able to complete the exercises properly.

After a year of teaching practice, the learning results of students have been changed. Students' abilities, knowledge, academic have been significantly improved in the community.

We used the method of questionnaire to verity the strategies in the community.

Questionnaire combined with the characteristics of network learning and learning metacognitive monitoring scale proposed.

Questionnaire is designed from two aspects. One is the network learning metacognitive monitoring capabilities; the other is the non-cognitive factors that affect metacognitive monitoring.

The respondents are the undergraduates majoring in navigational technology at Wuhan University of Technology. 300 questionnaires were given out, 280 valid papers of which have been taken back. Among the respondents, freshmen and sophomores respectively account for $58.6 \%$ and $41.4 \%$. In the survey, the options of the investigation on the meta-cognitive monitoring ability in online learning are in the form of 5-point Likert scale, asking respondents to identify which statement they are in accord with: never, occasionally, generally, often and always. The tools used to input and analyze the data are SPSS13.0 and Excel 2013. At the same time, the count and analysis are performed in terms of the plan making for automatic learning, the feedback of meta-cognitive monitoring, the evaluation of the result of study and the generalization and summarization of knowledge, as is shown in figure 1 .

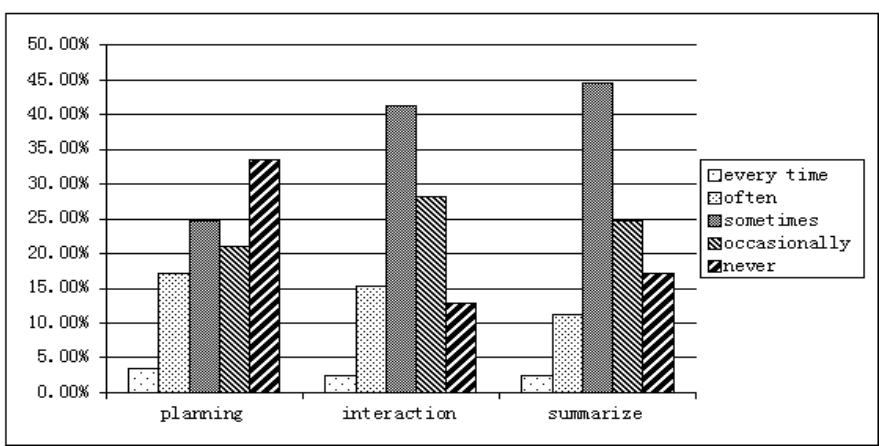

Figure 1.The results of metacognitive monitoring of automatic learning.

Initially, in the process of plan making of automatic learning, the college students who always plan and can be strict on it account for only 3.5\%, but who never plan constitutes up to $33.5 \%$; Secondly, the fluctuation of the subsequent statistics is relatively large. $86.4 \%$ of college students don't actively identify the result of their online learning or reflect on the learning process. Only $2.4 \%$ of college students always analyze and generalize, and actively take timely related exercises and practice to test the result of learning.

Therefore, the survey results show that students' metacognitive monitoring ability of automatic learning in the network is at a lower level. The development of various dimensions of metacognitive monitoring is unbalanced. Some dimensions (planning, preparation, consciousness, methods, feedback and summative dimension) are at a lower level. Motivation and metacognitive monitoring capability is extremely significant correlated. And the cause of success or failure is also closely related to the ability of metacognitive monitoring.

We used the method of questionnaire to verity the effect of teaching in the community. The respondents are the sophomores at Wuhan University of Technology. 120 questionnaires were given out, 120 valid papers of which have been taken back. Li Guohong \& ZhouQiang. 2014. The questionnaire is designed by the evaluation sheet. LaoLing \& LuoShuanglan. 2008. The result is shown in Table $1.84 .4 \%$ of students think their 
ability of automatic learning has been improved. Only $12.5 \%$ of students think the community is not helpful at all. For the learning results, $86.5 \%$ of students think they can evaluate their learning results timely, only $7.9 \%$ of students express that they cannot. $78.6 \%$ of students express that their interest has been improved and $21.4 \%$ don't think so. Finally, $86.8 \%$ of students are interested in the teaching model after the learning in the community. The vast majority of learners think that the teaching community is helpful for improving the self-learning ability and the learners can carry on personalize learning according to their actual situation, which inspire the interest in learning and enhance confidence in learning. Therefore, through a variety of teaching strategies and means, teachers and students interact with each other effectively and establish a rapport and harmonious relationship and create a good internet teaching environment.

Table 1 . The evaluation of the network interactive teaching community

\begin{tabular}{|c|c|c|c|c|c|}
\hline Items & Options & Percent (\%) & Items & Options & Percent (\%) \\
\hline \multirow{4}{*}{$\begin{array}{l}\text { Has the ability of } \\
\text { automatic study been } \\
\text { improved? }\end{array}$} & Yes & 62.4 & \multirow{4}{*}{$\begin{array}{l}\text { Has the interest of } \\
\text { study been improved? }\end{array}$} & Yes & 59.2 \\
\hline & A litter & 22 & & A litter & 19.4 \\
\hline & No & 12.5 & & No & 18.9 \\
\hline & Not sure & 3.1 & & Not sure & 2.5 \\
\hline \multirow{4}{*}{$\begin{array}{l}\text { Can you evaluate the } \\
\text { learning results at } \\
\text { regular intervals? }\end{array}$} & Yes & 63.4 & \multirow{4}{*}{$\begin{array}{l}\text { Are you interested in } \\
\text { teaching model? }\end{array}$} & Yes & 68.1 \\
\hline & A litter & 23.1 & & A litter & 18.7 \\
\hline & No & 7.9 & & No & 9.6 \\
\hline & Not sure & 5.6 & & Not sure & 3.6 \\
\hline
\end{tabular}

\section{CONCLUSIONS}

The theory of the construction of the interactive teaching community changed people's view that the knowledge is transferred in one-way, and made the key point of teaching design transferred from the object of knowledge (the content of knowledge) to the main body of knowledge (learners), and pay attention to the positive, active, dynamic function of learners. The teaching practice proves that the network interactive teaching community not only has the advantage of flexible space and time but also is conducive to the interactive activities. And it plays a positive role in stimulating interest in learning, setting up the process of learning, standardizing the assessment, improving the quality of learning, developing the learning ability, achieving network assessment, improving the quality of learning, developing the learning ability, achieving network assessment.

\section{ACKNOWLEDGMENT}

The work is supported by a teaching research project for Wuhan University of Technology (2013009) and a National Undergraduate Training Programs for Innovation and Entrepreneurship (20141049710006)

\section{REFERENCES}

[1] LaoLing \& LuoShuanglan. 2008. The investigation and analysis of the present situation of the metacognitive monitoring ability of college students in online study. Ji $x u$ jiao yu yan jiu: 95-97.

[2] ShenChunhua. 2006. Interactive teaching. Journal of Wuhan Engineering Instiute: 92-95.

[3] HuXuhuai \& YangZhihe \& ChenZhuanhong. 2012. The theory and application of the cooperative learning in interactive online teaching. Journal of Hunan Institute of Science and Technology: 77-81.

[4] LiGuohong \& ZhouQiang. 2014. The research of the interactive teaching model in the distance open course of open university. Journal of Hebei Radio \& TV University: 24-27. 